\section{Acute myocardial infarction in a young male}

An 18-year-old male presented with history of road traffic accident leading to multiple facial and skull bone fractures. There was no intracranial haemorrhage or active blood loss from any site. There was no evidence of chest injury. On examination he had tachycardia and persistent hypotension. An ECG revealed ST elevation in leads I, aVL, V1 and V2 with q right bundle branch block (qRBBB) pattern suggestive of acute anterior wall myocardial infarction. Echocardiogram showed severe left ventricular dysfunction with regional wall motion abnormalities in left anterior descending artery (LAD) and left circumflex artery (LCX) territories. An urgent angiogram showed thrombus in the proximal left main coronary artery (figure 1A) and thrombotic distal LAD occlusion. A diagnosis of road traffic accident with acute anterior wall myocardial infarction was established. He was put on intra-aortic balloon pump (IABP) support and mechanical ventilation and managed conservatively initially in view of risk of bleeding. Repeat angiogram showed resolution of thrombus with persistent dissection flap in the left main coronary artery (figure 1B). In view of persistent dissection flap, the left main was stented with drug eluting stent (figure $2 \mathrm{~A}, \mathrm{~B}$ ). Postprocedure, the patient was successfully weaned of IABP and mechanical ventilation. Subsequently, he was discharged and was doing well at last follow-up. Although his follow-up echocardiograms
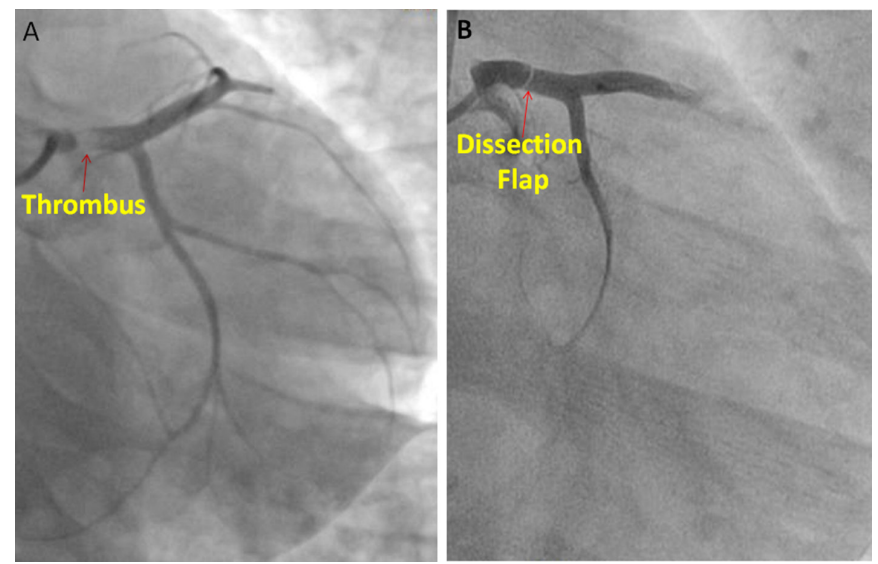

Figure 1 Coronary angiogram of the left coronary artery showing thrombus in the left main coronary artery (A) and repeat coronary angiogram showing thrombus resolution with dissection flap in left main (B).
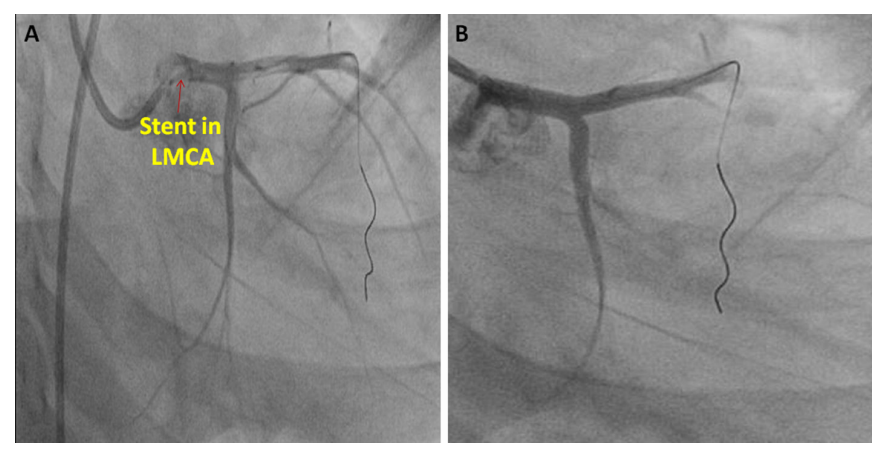

Figure 2 Coronary angiograms showing stent positioned in left main (A) and deployed stent in the left main coronary artery (B). LMCA, left main coronary artery.

at 6 months and 1 year show persistent severe left ventricular dysfunction, he remains in New York Heart Association (NYHA) functional class 1 .

Left main coronary dissections have been rarely reported with blunt chest traumas. ${ }^{12}$ Our patient although had no obvious chest trauma. Management should be tailored for individual patients keeping in mind the bleeding risk.

\section{Gajendra Dubey, Sharad Jain}

Department of Cardiology, U.N. Mehta Institute of Cardiology and Research Center, Ahmedabad, Gujrat, India

Correspondence to Dr Gajendra Dubey, U.N. Mehta Institute of Cardiology and Research Center, Civil Hospital, Ahmedabad, GJ 380016, India; gajendra.dubey119@ gmail.com

Contributors I assure that all the authors have contributed significantly and have read and approved the manuscript.

Funding This research received no specific grant from any funding agency in the public, commercial or not-for-profit sectors.

Competing interests None declared.

Patient consent Obtained.

Ethics approval Institute ethics committee.

Provenance and peer review Not commissioned; externally peer reviewed.

(c) Article author(s) (or their employer(s) unless otherwise stated in the text of the article) 2018. All rights reserved. No commercial use is permitted unless otherwise expressly granted.

\section{Check for updates}

To cite Dubey G, Jain S. Heart Asia 2018;10:1.

Heart Asia 2018:10:1. doi:10.1136/heartasia-2017-010992

\section{REFERENCES}

1 James MM, Verhofste M, Franklin C, et al. Dissection of the left main coronary artery after blunt thoracic trauma: case report and literature review. World J Emerg Surg 2010;5:21.

2 Boland J, Limet R, Trotteur G, et al. Left main coronary dissection after mild chest trauma. Favorable evolution with fibrinolytic and surgical therapies. Chest 1988;93:213-4. 